\title{
EFFECTS OF A PEPTIDE DERIVED FROM THE EXTREME CARBOXYL TERMINAL OF IL-8 ON IMMUNE RESPONSE GENES IN THE SHK-1 CELL LINE
}

\author{
Paula Santana ${ }^{1,2 *} \S$, Felipe Ramírez ${ }^{1 *}$, Fanny Guzmán ${ }^{1,2 *}$, Luis Mercado ${ }^{1,2 *}$ \\ ${ }^{1}$ Grupo de Marcadores Inmunológicos, Laboratorio de Genética e Inmunología Molecular, \\ Instituto de Biología, Pontificia Universidad Católica de Valparaíso, Valparaíso, Chile. \\ ${ }^{2}$ Núcleo Biotecnológico de Curauma (NBC), Pontificia Universidad Católica de \\ Valparaíso, Valparaíso, Chile.
}

\begin{abstract}
Interleukin (IL)-8 is a chemokine principally characterized for being a leukocyte chemotactic. Recently, our laboratory chemically synthesized an alpha-helical peptide derived from the extreme carboxyl terminal of IL-8 that, due to physicochemical characteristics and functions, also evidences an antimicrobial effector function against Gram-negative bacteria such as Aeromona salmonicidina, Pseudomona aeruginosa, and Escherichia coli. In higher vertebrates, there is ample evidence for the role that antimicrobial peptides play in regulating the immune response. Therefore, the objective of our study was to determine if the peptide derived from IL-8 affects relevant immune genes. For this, the transcriptional expression of immune response genes were assessed in the Atlantic salmon (Salmo salar) head kidney (SHK-1) cell line when stimulated with the synthetic antimicrobial peptide derived from IL-8. Our results evidenced that the expression of IL-6 slightly increased, while the expressions of iNOS and IL-1 $\beta$ decreased. Moreover, this peptide did not appear to affect the expressional levels of IL-8 or TNF $\alpha$. Our results suggest that this peptide could directly influence the genetic expression of leukocytes, such as macrophages, through a down- or upregulation of immune genes. In conclusion, the peptide derived from IL-8 would not only contribute towards limiting bacterial infection, but it would also have the ability to block macrophage activity and thereby likely participate in the end of the immune response. This studied was financed through Proyecto FONDECYT N 3150678
\end{abstract}

KEYWORDS: Atlantic salmon, antimicrobial peptide, chemokine, leucocytes, immune-relevant genes 
*These authors contributed equally to this work.

§ Corresponding author. Tel.: +56 322274837; E-mail address: paula.santana@ucv.cl 